\title{
Calpain is involved in cisplatin-induced endothelial injury in an in vitro three-dimensional blood vessel model
}

\author{
RYOJI EGUCHI ${ }^{1}$, YOSHIHIRO FUJIMORI ${ }^{1,2}$, TOSHIRO OHTA $^{3}$, \\ KAZUHIRO KUNIMASA ${ }^{4}$ and TAKASHI NAKANO ${ }^{1,2,5}$

\begin{abstract}
${ }^{1}$ Department of Thoracic Oncology and ${ }^{2}$ Cancer Center, Hyogo College of Medicine, Nishinomiya, Hyogo 663-8501;
${ }^{3}$ Department of Food and Nutritional Sciences, Graduate School of Nutritional and Environmental Sciences, University of Shizuoka, Shizuoka; ${ }^{4}$ Institute for World Health Development, Mukogawa Women's University;
\end{abstract} \\ ${ }^{5}$ Division of Respiratory Medicine, Department of Internal Medicine, Hyogo College of Medicine, Nishinomiya, Japan
}

Received June 18, 2010; Accepted August 6, 2010

DOI: 10.3892/ijo_00000780

\begin{abstract}
To study endothelial injury in vitro, we established a three-dimensional (3-D) blood vessel model in which human umbilical vein endothelial cells were grown in the presence of basic fibroblast growth factor and vascular endothelial growth factor. We then performed comparative studies on cisplatin (cis-platinum-diammine-dichloride, CDDP)-induced endothelial injury in 3-D and monolayer cultures. In 3-D culture, CDDP induced cell death and tube breakdown without DNA damage, whereas CDDP induced apoptosis accompanied by DNA damage in monolayer culture. CDDP also induced caspase- 3 activation in a concentrationdependent manner in both cultures. A broad-spectrum caspase inhibitor, zVAD-fmk, failed to prevent CDDP-induced cell death and tube breakdown in 3-D culture, whereas zVAD-fmk suppressed CDDP-induced apoptosis in monolayer culture. A calpain inhibitor, MDL28170, attenuated CDDP-induced cell death and tube breakdown in 3-D culture, but not apoptosis in monolayer culture. These results showed that calpain is involved in CDDP-induced endothelial injury in 3-D culture and there are significant differences in signaling pathways between 3-D and monolayer cultures.
\end{abstract}

\section{Introduction}

Antitumor agents can cause microvascular endothelial injury characterized by thrombotic microangiopathies, called thrombotic thrombocytopenic purpura, and hemolytic uremic syndrome (1). Cisplatin (cis-platinum-diammine-dichloride, CDDP) is a widely used chemotherapeutic agent against testicular, bladder, ovarian, head and neck, and lung cancer (2). CDDP causes renal dysfunction as a major side effect

Correspondence to: Dr Yoshihiro Fujimori, Cancer Center, Hyogo College of Medicine, 1-1 Mukogawa-cho, Nishinomiya, Hyogo 663-8501, Japan

E-mail: fuji-y@hyo-med.ac.jp

Key words: human umbilical vein endothelial cells, threedimensional culture, cisplatin, calpain, caspase and has also been reported to induce endothelial injury (3). CDDP compounds cross-link with DNA to disrupt the double helix $(4,5)$, leading to apoptosis which is believed to be the primary mechanism of CDDP cytotoxicity (6).

The p53 tumor suppressor protein plays a major role in growth arrest, DNA repair, senescence, differentiation and apoptosis (7). DNA damage caused by CDDP and other antitumor agents stabilize p53, which induces proapoptotic genes such as bax, and apoptosis when the DNA damage is particularly severe $(8,9)$.

Caspases and $\mathrm{Ca}^{2+}$-dependent calpains are both classified as cysteine proteases $(10,11)$. In response to apoptotic stimuli, caspases relay messages through so-called initiator caspases to effector (or execution) caspases, which then mediate apoptotic processes, such as externalization of phosphatidylserine and proteolysis (e.g., lamin) (12). Calpains are involved in maintenance and regulation of the cytoskelton and cell death $(10,11)$. The ubiquitous calpain isoforms, $\mu$-calpain and m-calpain, are abundantly expressed in human tissues. Calpains have been shown to cross-talk with caspases in CDDP-induced apoptosis in several cancer cell lines $(13,14)$.

We analyzed endothelial tube breakdown caused by hypoxia in a three-dimensional (3-D) blood vessel model in which human umbilical vein endothelial cells (HUVECs) were stimulated with phorbol 12-myristate 13-acetate (PMA) and fibroblast growth factor (FGF) to form capillary-like tubes in type I collagen $(15,16)$. In such a 3-D model, endothelial cells express genes/proteins in a manner observed in vivo $(17,18)$. PMA is an activator of protein kinase $\mathrm{C}$ known to promote angiogenesis (19). However, PMA is a non-physiological compound and it is therefore desirable to eliminate PMA from the 3-D model.

In this study, we first characterized an in vitro 3-D blood vessel model with vascular endothelial growth factor (VEGF) and basic FGF (bFGF) but no PMA with respect to the formation and maintenance of capillary-like tube and lumen structures. We then analyzed the effect of CDDP on HUVECs in 3-D culture in comparison to that in monolayer culture. We found that calpain is involved in endothelial injury and cell death caused by CDDP in 3-D culture but not in monolayer culture. 


\section{Materials and methods}

Cell culture and reagents. HUVECs isolated from human umbilical cord were purchased from Lonza Walkersville, Inc. (MD, USA) and cultured as previously reported (15). Briefly, cells were grown in HUVECs culture medium composed of MCDB-104 medium (Nihon Pharmaceutical, Tokyo, Japan) supplemented with $10 \%$ fetal bovine serum (Moregate, Brisbane, Australia), $100 \mathrm{ng} / \mathrm{ml}$ endothelial cell growth factor, $10 \mathrm{ng} / \mathrm{ml}$ epidermal growth factor (BD Biosciences, Bedford, MA), $100 \mu \mathrm{g} / \mathrm{ml}$ heparin, $25 \mu \mathrm{g} / \mathrm{ml}$ penicillin, $25 \mu \mathrm{g} / \mathrm{ml}$ streptomycin, and $50 \mu \mathrm{g} / \mathrm{ml}$ neomycin. Incubation was carried out at $37^{\circ} \mathrm{C}$ in $95 \%$ air and $5 \% \mathrm{CO}_{2}$. Type I collagen solution (Atelocollagen Bovine Dermis, IPC-30) was purchased from Koken (Tokyo, Japan). Other chemicals were purchased from Sigma (St. Louis, MO) unless otherwise stated.

Tube formation. Collagen gels were prepared using type I collagen at a concentration of $0.255 \%$. HUVECs were trypsinized, spun down from culture medium, mixed with collagen gels. For morphological observations and Western blot analysis, $140 \mu \mathrm{l}$ of collagen gel at $1.71 \times 10^{6}$ cells $/ \mathrm{ml}$ or $2.86 \times 10^{6}$ cells $/ \mathrm{ml}$ was added to each well of 48 -well culture plates (3-D culture). For cell viability analysis, $42 \mu 1$ of collagen gel at $2.86 \times 10^{6}$ cells $/ \mathrm{ml}$ was added to each well of 96-well culture plates (3-D culture). The mixture then was incubated at $37^{\circ} \mathrm{C}$ for $60 \mathrm{~min}$. For detailed morphological observations, cells $\left(1.0 \times 10^{5}\right.$ cells $\left./ \mathrm{cm}^{2}\right)$ were sandwiched between two layers of collagen gel in 24-well culture plates as described previously (sandwich culture) (16). Tube formation was induced in tube-induction medium composed of MCDB-104 medium and 199 medium at a 13:7 ratio, supplemented with $2 \%$ fetal bovine serum, $50 \mathrm{ng} / \mathrm{ml}$ human recombinant bFGF (Wako Pure Chemical, Osaka, Japan), $50 \mathrm{ng} / \mathrm{ml}$ human recombinant VEGF (Humanzyme, Chicago, IL), $25 \mu \mathrm{g} / \mathrm{ml}$ L-ascorbic acid, $25 \mu \mathrm{g} / \mathrm{ml}$ penicillin, $25 \mu \mathrm{g} / \mathrm{ml}$ streptomycin and $50 \mu \mathrm{g} / \mathrm{ml}$ neomycin. In some experiments, $10 \mathrm{nM}$ PMA was added to the tube-induction medium. Tubeinduction medium was added to 3-D culture for morphological observation and Western blot analysis, survival analysis, and sandwich method, in a volume of 260, 78 and $650 \mu 1$, respectively. Cells were then incubated for $48 \mathrm{~h}$ to induce tube formation.

Morphological observation. After experimental treatments, HUVECs grown in 3-D culture and sandwich culture were fixed with $1 \%$ glutaraldehyde overnight at $4^{\circ} \mathrm{C}$. The cells were stained with $0.1 \%$ toluidine blue in $30 \%$ methanol, destained, and observed under a light microscope (Nicon, Tokyo, Japan) for phase contrast images. For electron microscopic observations, the cells were dehydrated in a graded series of ethanol and then substituted with propylene oxide and embedded in epoxyresin (TAAB812, TAAB, UK) after fixation described above. Ultra thin sections $(0.08-\mu \mathrm{m}$ thick) were cut on a Leica Ultracut UCT ultramicrotome (Leica, Eien, Austria), mounted on formvar-coated copper grids (VECO, Eerbeek, The Netherlands), and stained with uranyl acetate (Merck, Frankfurt, Germany) and then with lead citrate. Sections were observed using a conventional TEM, JEM-1220 microscope (JEOL, Tokyo, Japan).
Cell viability analyses. Cell viability was determined using the Cell Counting Kit-8 (Dojindo, Tokyo, Japan) according to the manufacturer's protocol. Briefly, Water tetrazolium salt 8,2-(2-methoxy-4-nitrophenyl)-3-(4-nitrophenyl)-5(2,4-disulfophenyl)-2H-tetrazolium, monosodium salt was added in 3-D culture after CDDP treatments with or without zVAD(OMe)-fmk (Biomol, Plymouth Meeting, PA) or MDL28170 (Biomol). The compound is reduced by cellular dehydrogenases to form a water-soluble orange-colored formazan dye. The intensity of color developed was quantified using a micro plate reader (SPECTRAmax PLUS384, Molecular Devices, Sunnyvale, CA). Experiments were repeated in quadruplicate.

Treatments of HUVECs with CDDP and inhibitors. HUVECs $\left(5 \times 10^{4} /\right.$ well $)$ in monolayer culture were seeded in 12-well culture plates in $1 \mathrm{ml}$ of culture medium. The medium was changed to fresh tube-induction medium $(1 \mathrm{ml})$ after cell adhesion for $24 \mathrm{~h}$. HUVECs were then incubated further for 24-48 $\mathrm{h}$ in fresh tube-induction medium $(1 \mathrm{ml})$ supplemented with 12.5-50 $\mu \mathrm{M}$ CDDP, or vehicle (dimethylsulfoxide, DMSO) alone. For analysis of the effects of CDDP on HUVECs in 3-D culture, the tube-induction medium was aspirated after tube formation for $48 \mathrm{~h}$. For morphological observation and Western blot analysis, $400 \mu 1$ of fresh tubeinduction medium supplemented with 12.5-100 $\mu \mathrm{M}$ CDDP or DMSO or $120 \mu \mathrm{l}$ of it for survival analysis was added, and incubation continued further for 24-48 h. For inhibitor experiments, zVAD(OMe)-fmk and MDL28170 were added to the fresh tube-induction medium supplemented with CDDP or DMSO.

Flow cytometric analysis of apoptosis. Apoptosis of HUVECs in monolayer culture was analyzed by flow cytometry using an Annexin V (Ax)-FITC Kit (Medical \& Biological Laboratories Co. Ltd., Nagoya, Japan) according to the manufacturer's protocol. Briefly, HUVECs $\left(1 \times 10^{5}\right)$ treated with CDDP were trypsinized, washed with phosphatebuffered saline and then labeled with Ax-FITC and propidium iodide. The fluorescence intensity was measured using a Cytomics FC 500 flow cytometer and CXP software (Beckman Coulter, Inc., Fullerton, CA).

Western blotting. Western blotting was performed as described previously (16). All antibodies used were from Cell Signaling Technology (Beverly, MA) except those against Bax, p53 (both from BD Biosciences, San Jose, CA) and GAPDH (Santa Cruz Biotechnology, Santa Cruz, CA).

Statistical analyses. All data are expressed as the means \pm standard error (SE) of at least three independent experiments. Comparisons between two groups were performed using Student's unpaired t-test $\left({ }^{*} \mathrm{p}<0.05,{ }^{* *} \mathrm{p}<0.01,{ }^{* * *} \mathrm{p}<0.005\right)$.

\section{Results}

VEGF supports bFGF-induced formation and maintenance of capillary-like tube and lumen structures in the absence of $P M A$ in 3-D culture. We examined tube formation in the presence of bFGF, VEGF, PMA and their combination in 3 -D culture. At a cell density of $1.71 \times 10^{6} \mathrm{cells} / \mathrm{ml}$ used in our 
A $\left(1.71 \times 10^{6} \mathrm{cells} / \mathrm{ml}\right)$

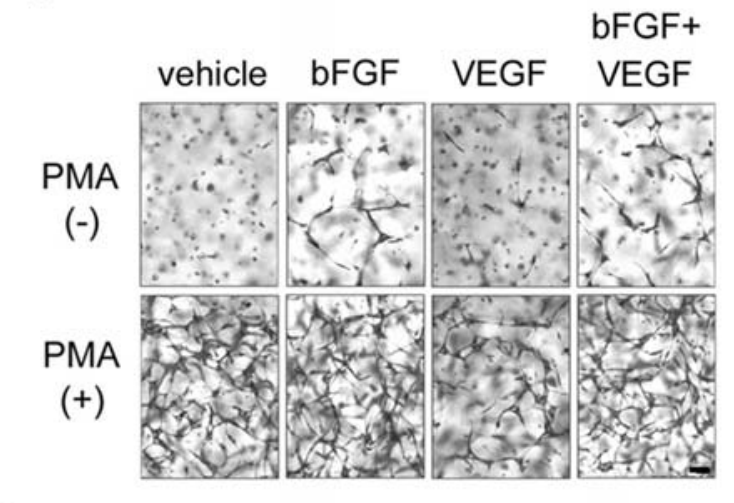

C

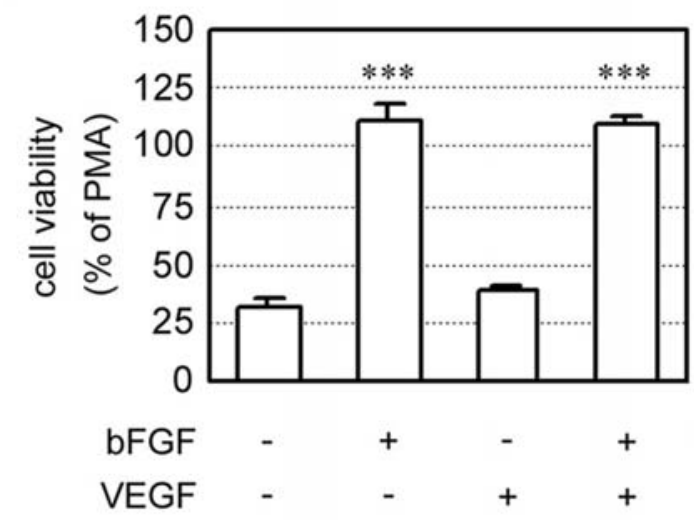

D

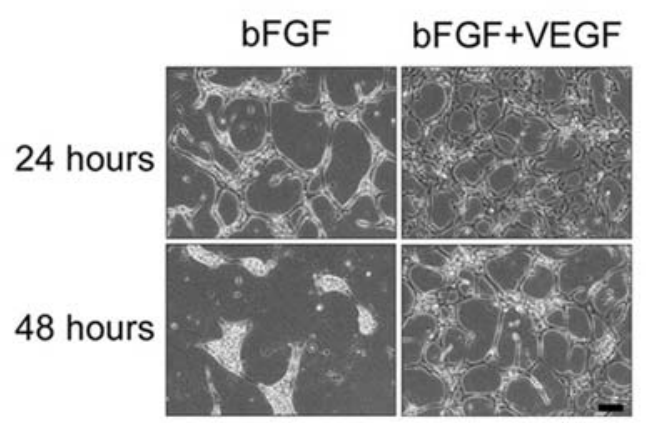

\section{B $\left(2.86 \times 10^{6} \mathrm{cells} / \mathrm{ml}\right)$}

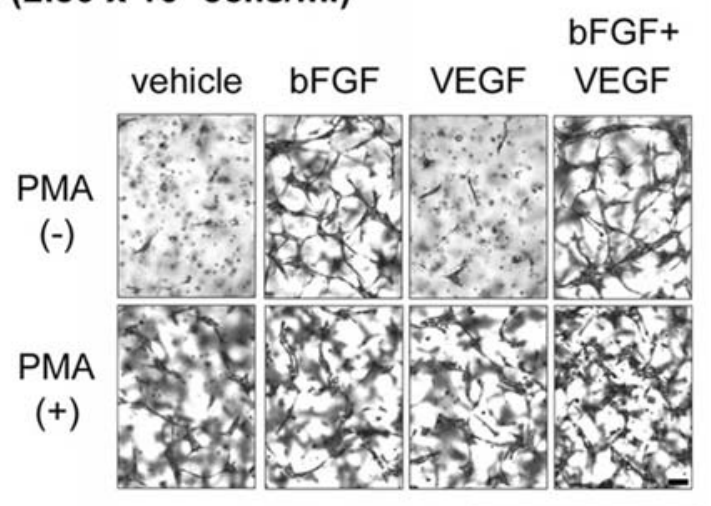

E

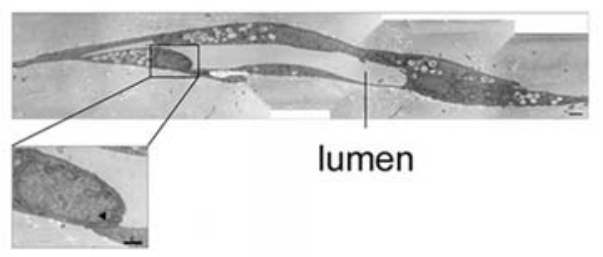

$\mathbf{F}$

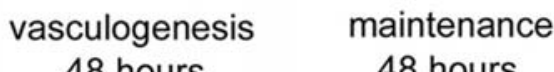
48 hours

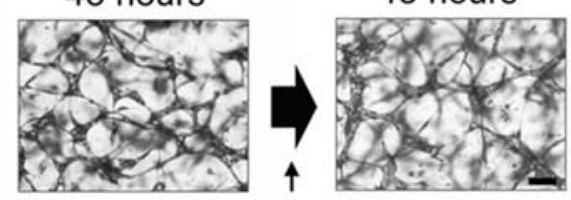

addtion fresh bFGF and VEGF

G

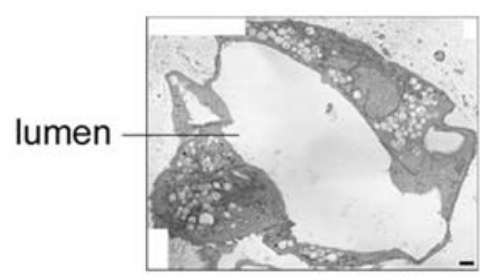

Figure 1. bFGF, VEGF and a cell density play a crucial role in the formation and maintenance of capillary-like structures in 3-D culture. (A) PMA, but not with bFGF and/or VEGF, induces the formation of capillary-like tube structures. HUVECs at $1.71 \times 10^{6} \mathrm{cells} / \mathrm{ml}$ in 48 -well culture plates were treated with $50 \mathrm{ng} / \mathrm{ml}$ bFGF and/or $50 \mathrm{ng} / \mathrm{ml}$ VEGF, with or without $10 \mathrm{nM}$ PMA for $48 \mathrm{~h}$. The bar indicates $100 \mu \mathrm{M}$. (B) bFGF has a crucial role in tube formation in the absence of PMA. Tube formation at $2.86 \times 10^{6}$ cells $/ \mathrm{ml}$ in 48 -well culture plates was induced by bFGF, and/or VEGF, with or without PMA for $48 \mathrm{~h}$. The bar indicates $100 \mu \mathrm{m}$. (C) bFGF, but not VEGF, increases cell viability during tube formation. HUVECs at $2.86 \times 10^{6}$ cells $/ \mathrm{ml}$ were incubated with bFGF and/or VEGF in 96-well culture plates for $48 \mathrm{~h}$. Cell viability was assessed using WST-8 as described in Materials and methods. (D) VEGF is required for bFGF-induced tube formation. Tube structures were formed by bFGF with or without VEGF using a sandwich culture method at $1.0 \times 10^{5}$ cells $/ \mathrm{cm}^{2}$ in $24-w e l l$ culture plates for 24-48 h. The bar represents $100 \mu \mathrm{m}$. (E) Lumen structures are formed by bFGF and VEGF. Lumen formation was induced in HUVEC at 2.86x10 cells $/ \mathrm{ml}$ in 48-well culture plates by bFGF and VEGF for $48 \mathrm{~h}$. Cells were fixed with glutaraldehyde and thin sections were prepared and examined under an electron microscopy (magnification x400) as described in Materials and methods. The arrowhead points to a cell-cell junctional contact. The bar represents $1 \mu \mathrm{m}$. (F) Tube structures are maintained by bFGF and VEGF. HUVECs were incubated in tube-induction medium in the presence of bFGF and VEGF for $48 \mathrm{~h}$, then the medium was changed to the fresh tube-induction medium, and incubation continued for additional $48 \mathrm{~h}$. The bar indicates $100 \mu \mathrm{m}$. (G) Lumen structures are maintained by bFGF and VEGF. Lumen structures after $96 \mathrm{~h}$ of incubation were cut into thin sections and examined under an electron microscope (magnification x3000). The bar indicates $1 \mu \mathrm{m}$. The experiments in A, B, D, E, F and G were performed three times and representative data are shown.

earlier study $(15,16)$, PMA was indispensable for induction of tube network formation (Fig. 1A). At a higher cell density of $2.86 \times 10^{6}$ cells $/ \mathrm{ml}$, bFGF but not VEGF markedly induced interconnected networks of capillary-like tubes in the absence of PMA (Fig. 1B). Cell viability was also increased by bFGF and not by VEGF (Fig. 1C). Thus, the requirement of PMA in tube formation in 3-D culture depends on a cell density, and bFGF alone is able to initiate tube formation in the appropriate cell density. We investigated the role of VEGF in bFGF-induced tube formation using the sandwich culture method (Fig. 1D). Although tube formation initiated by bFGF was broken down at $48 \mathrm{~h}$ in the absence of VEGF, 


\section{3-D culture}

A

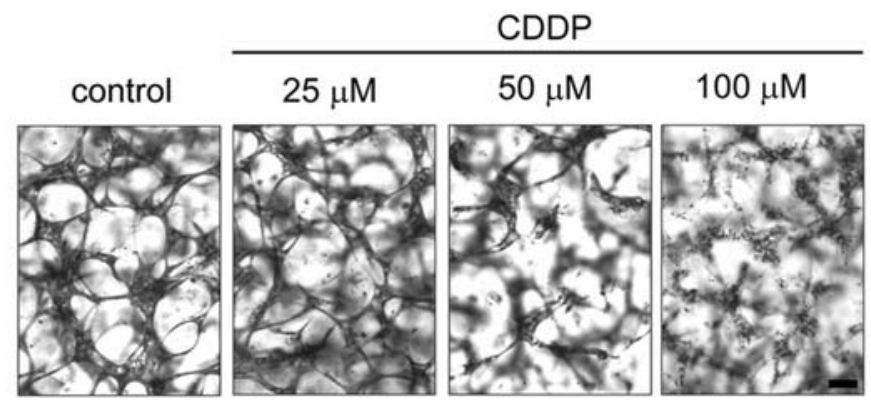

B

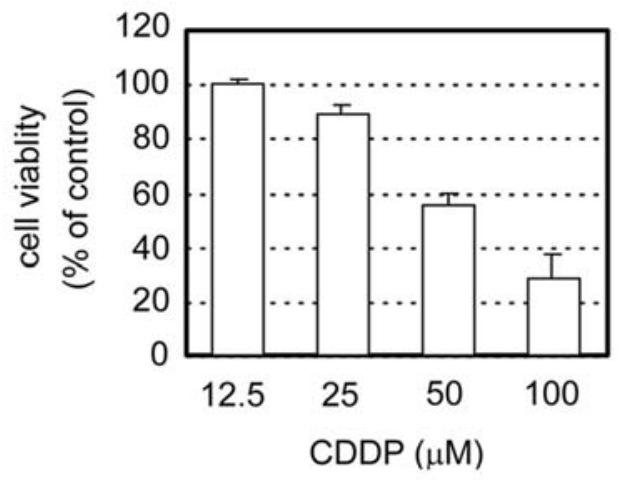

C

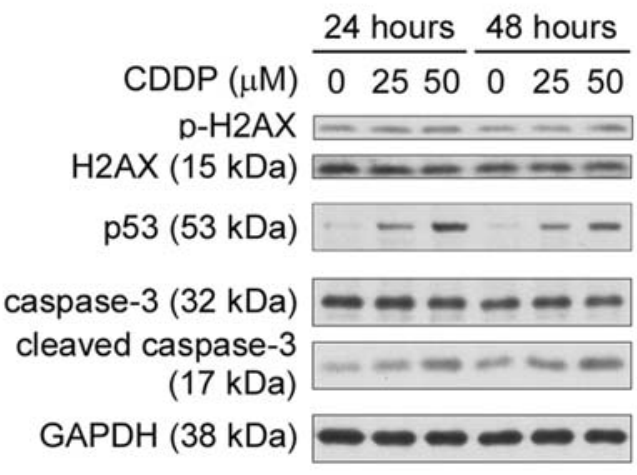

\section{monolayer culture}

D

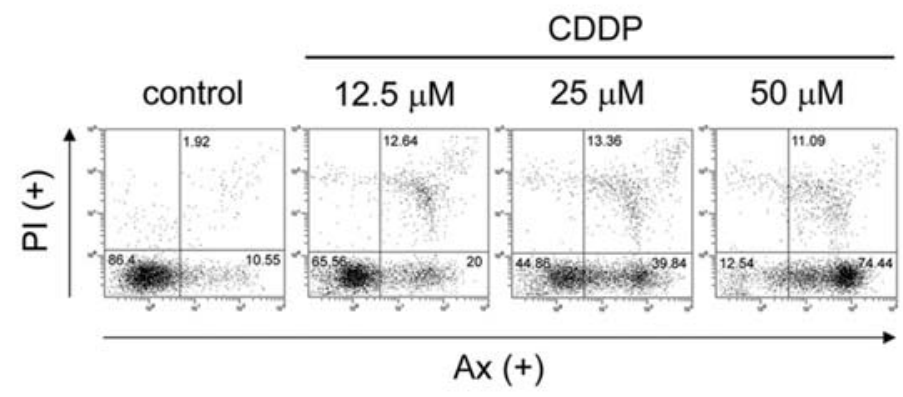

E

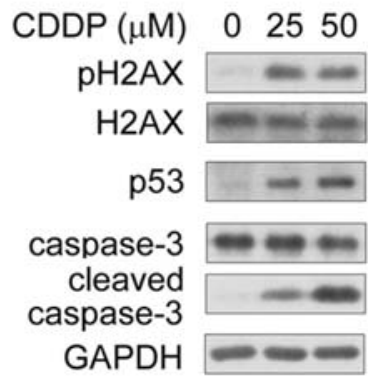

Figure 2. Cisplatin (CDDP) induces cell death and tube breakdown in 3-D culture and apoptosis in monolayer culture. (A) CDDP induces tube breakdown in 3-D culture. Capillary-like tube structures of HUVECs were treated with CDDP for $48 \mathrm{~h}$ at the indicated concentrations. The bar indicates $100 \mu \mathrm{m}$. (B) Cell death is induced by CDDP in 3-D culture. Tube-forming HUVECs were treated with the indicated concentrations of CDDP for $48 \mathrm{~h}$, and cell viability was assessed using WST-8. (C) p53 expression and caspase-3 activation are induced by CDDP without DNA damage in 3-D culture. Cell extracts were prepared from tube-forming HUVECs that had been treated with the indicated concentrations of CDDP for 24 or $48 \mathrm{~h}$, and analyzed for indicated proteins by Western blotting. (D) CDDP induces apoptosis in monolayer culture. HUVECs were treated with CDDP at the indicated concentrations for $48 \mathrm{~h}$. The percentage of viable (bottom left), early apoptotic (bottom right), late apoptotic (top right) or necrotic (top left) cells was detected using flow cytometry after double staining with Annexin V (Ax)-FITC and propidium iodide (PI). (E) CDDP induces DNA damage, followed by p53 expression and caspase-3 activation, in monolayer culture. Cell extracts were prepared from HUVECs treated with CDDP at the indicated concentrations for $24 \mathrm{~h}$. The experiments in A, C and E were performed three times and the representative data are shown.

VEGF supported bFGF-initiated tube formation up to $48 \mathrm{~h}$ to complete formation of interconnected networks. Furthermore, we observed the formation of cell-to-cell adhesions and lumen structures composed of multiple HUVECs in the presence of bFGF and VEGF (Fig. 1E). To examine the maintenance of tube and lumen structures in the presence of bFGF and VEGF in 3-D culture, $48 \mathrm{~h}$ cultures carrying tube structures were further incubated for $48 \mathrm{~h}$ with fresh bFGF and VEGF. Capillary-like tube and lumen structures were maintained to the end of the second $48 \mathrm{~h}$ incubation (Fig. 1F and $\mathrm{G})$. These results suggest that a combination of bFGF and VEGF is able to maintain tube and lumen structures in 3-D culture.

CDDP induces cell death and tube breakdown in 3-D culture. To investigate CDDP-induced endothelial injury, we treated with CDDP to the 3-D culture model in which capillarylike tube and lumen structures were formed. CDDP was found to cause breakdown of tube structures in a concentrationdependent manner (Fig. 2A). Cell viability was also reduced by CDDP in 3-D culture (Fig. 2B), suggesting that CDDPinduced tube breakdown is caused by cell death. In the presence 
3-D culture

A

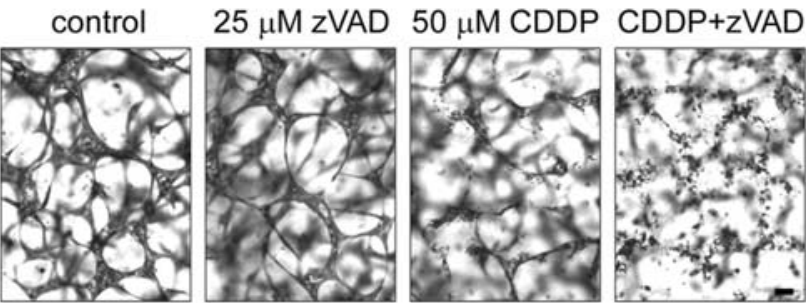

B

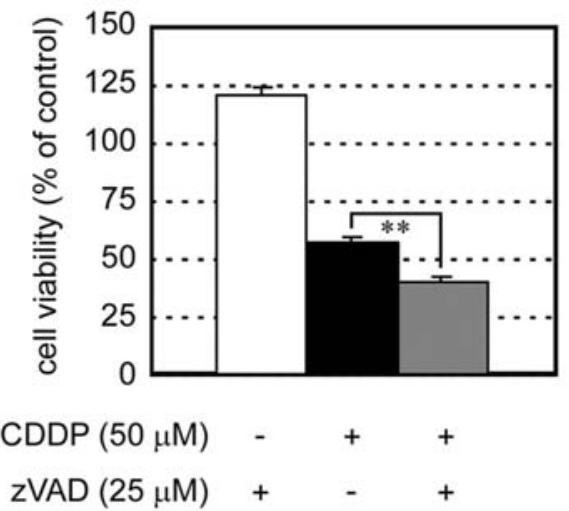

C

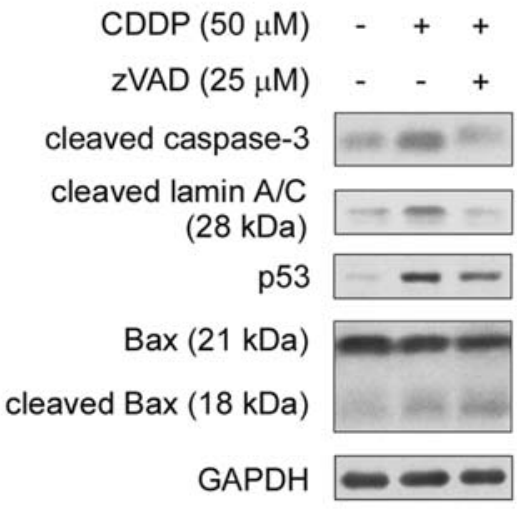

\section{monolayer culture}

D

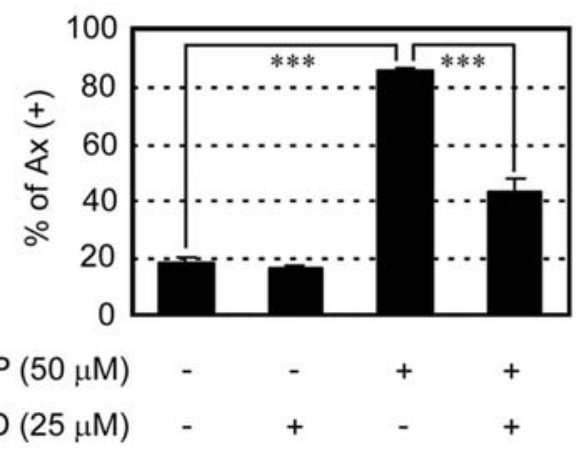

E

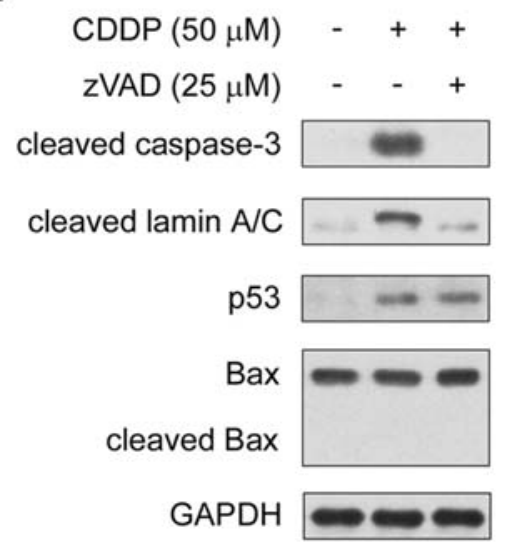

Figure 3. Inhibition of the caspase cascade fails to suppress CDDP-induced cell death and tube breakdown in 3-D culture, but does suppress CDDP-induced apoptosis in monolayer culture. (A) A broad-spectrum caspase inhibitor, zVAD(OMe)-fmk (zVAD), facilitates CDDP-induced tube breakdown in 3-D culture. Tube-forming HUVECs were treated with $50 \mu \mathrm{M}$ CDDP and/or $25 \mu \mathrm{M}$ zVAD for $48 \mathrm{~h}$. The bar indicates $100 \mu \mathrm{m}$. (B) CDDP-induced cell death is enhanced by zVAD in 3-D culture. Tube-forming HUVECs were treated with $50 \mu \mathrm{M}$ CDDP and/or $25 \mu \mathrm{M}$ zVAD for $48 \mathrm{~h}$. (C) zVAD suppresses the CDDPinduced caspase cascade and p53 expression, but not Bax cleavage, in 3-D culture. Cell extracts were prepared from tube-forming HUVECs treated with $50 \mu \mathrm{M}$ CDDP with or without $25 \mu \mathrm{M}$ zVAD for $24 \mathrm{~h}$. (D) CDDP-induced apoptosis is suppressed by zVAD in monolayer culture. HUVECs were treated with $50 \mu \mathrm{M}$ CDDP and/or $25 \mu \mathrm{M}$ zVAD for $48 \mathrm{~h}$. The percentage of apoptotic cells was determined using flow cytometry after staining with Ax-FITC. (E) The CDDP-induced caspase cascade, but not p53 expression, is inhibited by zVAD in monolayer culture. Cell extracts were prepared from HUVECs treated with $50 \mu \mathrm{M} \mathrm{CDDP}$ with or without $25 \mu \mathrm{M} \mathrm{zVAD}$ for $24 \mathrm{~h}$. The experiments in $\mathrm{A}, \mathrm{C}$ and $\mathrm{E}$ were performed three times and the representative data are shown.

of CDDP, levels of p53 and cleaved caspase-3, but not levels of phosphorylated $\mathrm{H} 2 \mathrm{AX}$ as a DNA damage marker, increased (Fig. 2C), indicating that cell death of HUVECs in 3-D culture was not due to DNA damage. In monolayer culture, flow cytometric analysis showed that CDDP treatment increased the number of annexin $\mathrm{V}(\mathrm{Ax})$-positive cells in a concentrationdependent manner (Fig. 2D). Western blot analysis showed increases in levels of phosphorylated $\mathrm{H} 2 \mathrm{AX}$, p53 and cleaved caspase-3 in the presence of CDDP in monolayer culture (Fig. 2E), suggesting that CDDP induces apoptosis of HUVECs.
Caspase regulates CDDP-induced apoptosis in monolayer culture, but not CDDP-induced cell death and tube breakdown in 3-D culture. We examined whether $\mathrm{zVAD}(\mathrm{OMe})$-fmk (zVAD), a broad-spectrum caspase inhibitor, could suppress CDDP-induced cell death and tube breakdown in 3-D culture. Unexpectedly, CDDP treatment together with zVAD in 3-D culture facilitated CDDP-induced tube breakdown (Fig. 3A). The CDDP-induced decrease in cell viability was also significantly enhanced by zVAD (Fig. 3B). However, cleavage of both caspase- 3 and lamin $\mathrm{A} / \mathrm{C}$, and p53 expression were suppressed by zVAD (Fig. 3C). Intriguingly, Bax protein levels 


\section{3-D culture}

A control $\quad 1 \mu \mathrm{M}$ MDL $50 \mu \mathrm{M}$ CDDP $\quad \mathrm{CDDP}+\mathrm{MDL}$

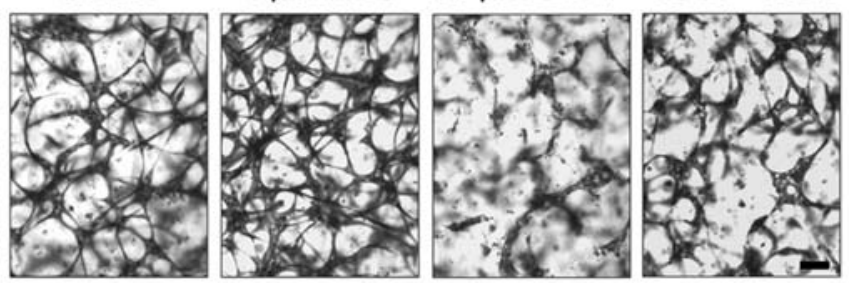

B

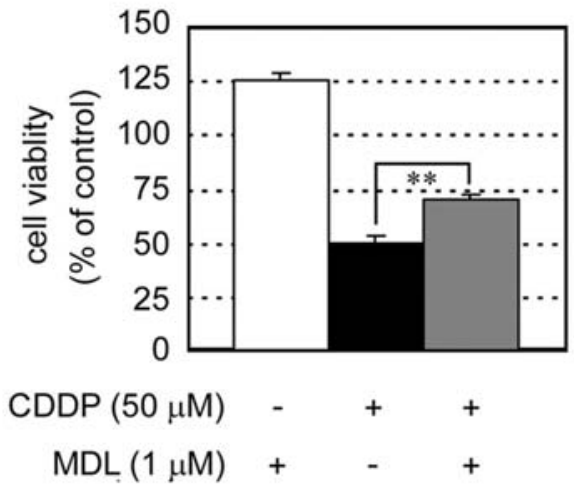

C

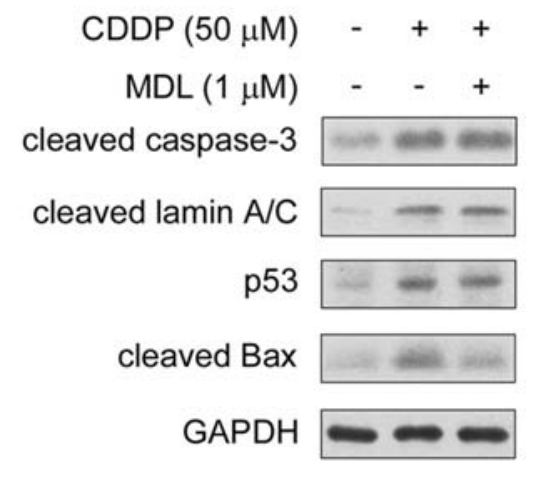

\section{monolayer culture}

D

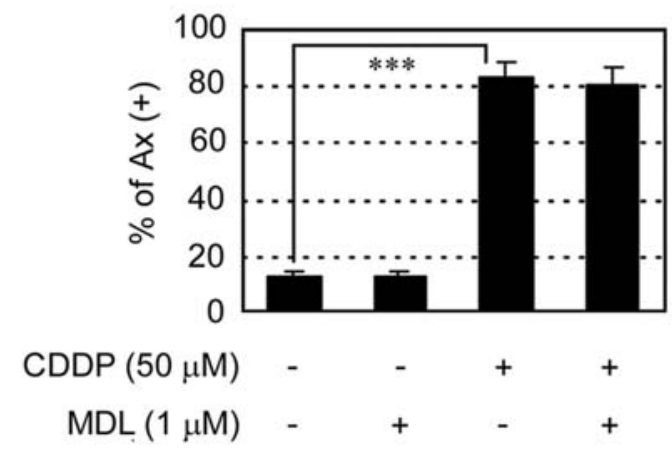

E

\begin{tabular}{|c|c|c|c|}
\hline CDDP $(50 \mu \mathrm{M})$ & - & + & + \\
\hline $\operatorname{MDL}(1 \mu \mathrm{M})$ & - & - & + \\
\hline cleaved caspase-3 & & $=8$ & 8 \\
\hline cleaved lamin A/C & & $m$ & $=$ \\
\hline p53 & & 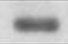 & $\Leftrightarrow$ \\
\hline GAPDH & $=$ & $=$ & $\Leftrightarrow$ \\
\hline
\end{tabular}

Figure 4. Calpain inhibition attenuates CDDP-induced cell death and tube breakdown in 3-D culture but not CDDP-induced apoptosis in monolayer culture. (A) A calpain inhibitor, MDL28170 (MDL), attenuates CDDP-induced tube breakdown in 3-D culture. Tube-forming HUVECs were treated with 50 $\mu \mathrm{M}$ CDDP and/or $1 \mu \mathrm{M}$ MDL for $48 \mathrm{~h}$. The bar indicates $100 \mu \mathrm{m}$. (B) MDL suppresses CDDP-induced cell death in 3-D culture. Tube-forming HUVECs were treated with $50 \mu \mathrm{M}$ CDDP and/or $1 \mu \mathrm{M}$ MDL for $48 \mathrm{~h}$. (C) Bax cleavage, but not CDDP-induced cellular apoptotic responses, is inhibited by MDL in 3-D culture. Cell extracts were prepared from tube-forming HUVECs treated with $50 \mu \mathrm{M}$ CDDP with or without $1 \mu \mathrm{M}$ MDL for $24 \mathrm{~h}$. (D) MDL fails to attenuate CDDP-induced apoptosis in monolayer culture. HUVECs were treated with $50 \mu \mathrm{M}$ CDDP and/or $1 \mu \mathrm{M}$ MDL for $48 \mathrm{~h}$. (E) CDDP-induced cellular apoptotic responses are not suppressed by MDL in monolayer culture. Cell extracts were prepared from HUVECs treated with $50 \mu \mathrm{M}$ CDDP with or without $1 \mu \mathrm{M}$ MDL for $24 \mathrm{~h}$. The experiments in A, C and $\mathrm{E}$ were performed three times and the representative data are shown.

showed little change following zVAD treatment, whereas cleavage of Bax (p18 product) was increased by CDDP with or without zVAD. In contrast, zVAD significantly suppressed the CDDP-induced increase in Ax-positive cells in monolayer culture (Fig. 3D). zVAD also markedly inhibited the cleavage of caspase- 3 and lamin $\mathrm{A} / \mathrm{C}$, but not $\mathrm{p} 53$ expression, induced by CDDP (Fig. 3E). These results suggest that the caspasecascade regulates CDDP-induced apoptosis in monolayer culture, but not CDDP-induced cell death and tube breakdown in 3-D culture.

Calpain partially regulates $C D D P$-induced cell death and tube breakdown in 3-D culture. It has been reported that Bax
$(21 \mathrm{kDa})$ is cleaved by calpain to generate an $18 \mathrm{kDa}$ product $(20,21)$. To investigate whether calpain is involved in CDDPinduced cell death and tube breakdown, we treated HUVECs in 3-D culture with CDDP together with MDL28170 (MDL), a $\mu$ - and m-calpain inhibitor. MDL attenuated CDDP-induced tube breakdown (Fig. 4A) and significantly suppressed CDDP-induced decrease in cell viability (Fig. 4B). MDL suppressed the cleavage of Bax, but had little effect on CDDP-induced p53 expression and cleavage of caspase-3 and lamin $\mathrm{A} / \mathrm{C}$ (Fig. 4C). In contrast, in monolayer culture, MDL had little effect on the CDDP-induced increase in Axpositive cells (Fig. 4D) and also failed to attenuate CDDPinduced cellular apoptotic responses (Fig. 4E). These data 


\section{endothelial cells in monolayer culture}

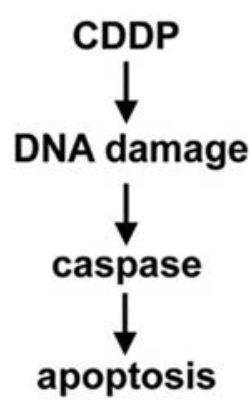

Figure 5. CDDP-induced endothelial injury is regulated by distinct mechanisms in monolayer and 3-D cultures. In monolayer culture, CDDP induces DNA damage, which results in caspase-dependent apoptosis. In 3-D culture, CDDP induces calpain activation followed by cell death and tube breakdown. CDDP-induced cell death is attenuated by inhibition of calpain activity, only partially. These results imply that: i) effects of CDDP on endothelial cells are different between monolayer and 3-D cultures, and ii) CDDPinduced cell death and tube breakdown in 3-D culture are regulated by both calpain-dependent and -independent mechanisms.

showed that calpain is involved in CDDP-induced cell death in 3-D culture, but not in monolayer culture.

\section{Discussion}

CDDP is a widely used chemotherapeutic agent for cancer therapy. However, CDDP is known to induce vascular damages as its side effect $(22,23)$. In the past, we have performed functional analysis of endothelial cells using an in vitro $3-\mathrm{D}$ blood vessel model that mimics in vivo blood vessel $(15,16)$. In the present study, we refined this 3-D blood vessel model to be used for analysis of CDDP-induced endothelial injury. We compared the effect of CDDP on HUVECs in 3-D and monolayer cultures, and found that there are significant differences in signaling pathways between 3-D and monolayer cultures.

Recent reports have shown that tube formation in HUVECs is induced by combinations of bFGF, VEGF and PMA (24). Ilan et al have reported that bFGF with or without VEGF fails to induce tube formation but PMA alone does (19), indicating that PMA is essential for the formation of vascular vessels in 3-D culture. VEGF has been reported to function as a survival factor (25). In this study, we found that bFGF was able to induce capillary-like tube structures in the absence of PMA at a cell density higher than that used previously, and that VEGF supported bFGF-induced tube formation and the maintenance of capillary-like tube and lumen structures. Our results also suggest that the cell density is a critical factor for the formation and maintenance of capillary-like structures in the presence of bFGF and VEGF. The 3-D model without PMA would provide a means better suited for studying endothelial cell functions.

Using this model, we found that caspase cascade was not involved in CDDP-induced cell death and tube breakdown, although CDDP induced caspase-dependent apoptosis in monolayer culture, as reported with cancer cells (26-28). Several studies have also reported that CDDP-induced cell death is regulated by calpains in endothelial and cancer cells in monolayer culture $(29,30)$. However, our study showed that this is not the case in monolayer culture, and rather calpain is related to CDDP-induced cell death in 3-D culture. These differences may reflect the fact that endothelial cells in 3-D culture function in a manner similar to those in vivo, while endothelial cells in monolayer culture manifest mainly proliferating activity.

It has been reported that p53 is not required for CDDPinduced apoptosis in renal tubular cells $(31,32)$. We showed here that p53 expression is increased by CDDP in both monolayer and 3-D cultures. However, we also found that CDDP-induced apoptosis in monolayer culture cannot be suppressed by pifithrin- $\alpha$, a p53 inhibitor (data not shown). These results suggest that p53 is not required for CDDPinduced cell death of endothelial cells.

In this study, we modified an in vitro 3 -D blood vessel model to allow the formation and maintenance of capillary-like tube and lumen structures in the presence of only physiological growth factors. In this model, our results show that CDDPinduced cell death and tube breakdown is partially regulated by calpain, while caspases caused CDDP-induced apoptosis in monolayer culture (Fig. 5). Our results in 3-D culture indicate that calpain may be involved in CDDP-induced endothelial injury in vivo.

\section{Acknowledgements}

We are grateful to Ms. Ritsuko Fujimoto, Ms. Hiromi Takeda, Ms. Yumiko Fujita and Ms. Kumi Futawaka for their excellent technical assistance.

\section{References}

1. Medina PJ, Sipols JM and George JN: Drug-associated thrombotic thrombocytopenic purpura-hemolytic uremic syndrome. Curr Opin Hematol 8: 286-293, 2001.

2. Taguchi T, Nazneen A, Abid MR and Razzaque MS: Cisplatinassociated nephrotoxicity and pathological events. Contrib Nephrol 148: 107-121, 2005.

3. Harrell RM, Sibley R and Vogelzang NJ: Renal vascular lesions after chemotherapy with vinblastine, bleomycin, and cisplatin. Am J Med 73: 429-433, 1982.

4. Chao CC, Shieh TC and Huang H: Use of a monoclonal antibody to detect DNA damage caused by the anticancer drug cis-diamminedichloroplatinum (II) in vivo and in vitro. FEBS Lett 354: 103-109, 1994.

5. Burstyn JN, Heiger-Bernays WJ, Cohen SM and Lippard SJ: Formation of cis-diamminedichloroplatinum(II) 1,2-intrastrand cross-links on DNA is flanking-sequence independent. Nucleic Acids Res 28: 4237-4243, 2000.

6. Fisher DE: Apoptosis in cancer therapy: crossing the threshold. Cell 78: 539-542, 1994.

7. Fuertesa MA, Castillab J, Alonsoa C and Perez JM: Cisplatin biochemical mechanism of action: from cytotoxicity to induction of cell death through interconnections between apoptotic and necrotic pathways. Curr Med Chem 10: 257-266, 2003.

8. Miyashita T and Reed JC: Tumor suppressor p53 is a direct transcriptional activator of the human bax gene. Cell 80: 293-299, 1995.

9. Zhou BB and Elledge SJ: The DNA damage response: putting checkpoints in perspective. Nature 408: 433-439, 2000.

10. Wang KK: Calpain and caspase: can you tell the difference? Trends Neurosci 23: 20-26, 2000.

11. Harwood SM, Yaqoob MM and Allen DA: Caspase and calpain function in cell death: bridging the gap between apoptosis and necrosis. Ann Clin Biochem 42: 415-431, 2005.

12. Cohen GM: Caspases: the executioners of apoptosis. Biochem $\mathrm{J}$ 326: 1-16, 1997. 
13. Del Bello B, Moretti D, Gamberucci A and Maellaro E: Crosstalk between calpain and caspase-3/-7 in cisplatin-induced apoptosis of melanoma cells: a major role of calpain inhibition in cell death protection and p53 status. Oncogene 26: 2717-2726, 2007.

14. Liu L, Xing D and Chen WR: Micro-calpain regulates caspasedependent and apoptosis inducing factor-mediated caspaseindependent apoptotic pathways in cisplatin-induced apoptosis Int J Cancer 125: 2757-2766, 2009.

15. Eguchi R, Suzuki A, Miyakaze S, Kaji K and Ohta T: Hypoxia induces apoptosis of HUVECs in an in vitro capillary model by activating proapoptotic signal p38 through suppression of ERK1/2. Cell Signal 19: 1121-1131, 2007.

16. Ohta T, Eguchi R, Suzuki A, Miyakaze S, Ayuzawa R and Kaji K: Hypoxia-induced apoptosis and tube breakdown are regulated by $\mathrm{p} 38$ MAPK but not by caspase cascade in an in vitro capillary model composed of human endothelial cells. J Cell Physiol 211: 673-681, 2007.

17. Glienke J, Schmitt AO, Pilarsky C, Hinzmann B, Weiss B, Rosenthal A and Thierauch KH: Differential gene expression by endothelial cells in distinct angiogenic states. Eur J Biochem 267: 2820-2830, 2000

18. Bell SE, Mavila A, Salazar R, Bayless KJ, Kanagala S, Maxwell SA and Davis GE: Differential gene expression during capillary morphogenesis in 3D collagen matrices: regulated expression of genes involved in basement membrane matrix assembly, cell cycle progression, cellular differentiation and G-protein signaling. J Cell Sci 114: 2755-2773, 2001.

19. Ilan N, Mahooti S and Madri JA: Distinct signal transduction pathways are utilized during the tube formation and survival phases of in vitro angiogenesis. J Cell Sci 111: 3621-3631, 1998.

20. Gao G and Dou QP: N-terminal cleavage of bax by calpain generates a potent proapoptotic $18-\mathrm{kDa}$ fragment that promotes bcl-2-independent cytochrome $\mathrm{C}$ release and apoptotic cell death. J Cell Biochem 80: 53-72, 2000.

21. Cao X, Deng X and May WS: Cleavage of Bax to p18 Bax accelerates stress-induced apoptosis, and a cathepsin-like protease may rapidly degrade p18 Bax. Blood 102: 2605-2614, 2003.
22. Ito $\mathrm{H}$, Okafuji $\mathrm{T}$ and Suzuki T: Vitamin $\mathrm{E}$ prevents endothelial injury associated with cisplatin injection into the superior mesenteric artery of rats. Heart Vessels 10: 178-184, 1995.

23. Icli F, Karaoguz H, Dincol D, Demirkazik A, Gunel N, Karaoguz R and Uner A: Severe vascular toxicity associated with cisplatin-based chemotherapy. Cancer 72: 587-593, 1993.

24. Koh W, Stratman AN, Sacharidou A and Davis GE: In vitro three dimensional collagen matrix models of endothelial lumen formation during vasculogenesis and angiogenesis. Methods Enzymol 443: 83-101, 2008.

25. Byrne AM, Bouchier-Hayes DJ and Harmey JH: Harmey, angiogenic and cell survival functions of vascular endothelial growth factor (VEGF). J Cell Mol Med 9: 777-794, 2005.

26. Wang J, Ladrech S, Pujol R, Brabet P, van de Water TR and Puel JL: Caspase inhibitors, but not c-Jun NH2-terminal kinase inhibitor treatment, prevent cisplatin-induced hearing loss. Cancer Res 64: 9217-9224, 2004.

27. Seki K, Yoshikawa H, Shiiki K, Hamada Y, Akamatsu N and Tasaka K: Cisplatin (CDDP) specifically induces apoptosis via sequential activation of caspase-8, -3 and -6 in osteosarcoma. Cancer Chemother Pharmacol 45: 199-206, 2000.

28. Kuwahara D, Tsutsumi K, Kobayashi T, Hasunuma T and Nishioka K: Caspase-9 regulates cisplatin-induced apoptosis in human head and neck squamous cell carcinoma cells. Cancer Lett 148: 65-71, 2000.

29. Dursun B, He Z, Somerset H, Oh DJ, Faubel S and Edelstein CL: Caspases and calpain are independent mediators of cisplatininduced endothelial cell necrosis. Am J Physiol Renal Physiol 291: F578-F587, 2006.

30. Splettstoesser F, Florea AM and Busselberg D: IP(3) receptor antagonist, 2-APB, attenuates cisplatin induced $\mathrm{Ca}^{2+}$-influx in HeLa-S3 cells and prevents activation of calpain and induction of apoptosis. Br J Pharmacol 151: 1176-1186, 2007.

31. Cummings BS and Schnellmann RG: Cisplatin-induced renal cell apoptosis: caspase 3-dependent and -independent pathways. J Pharmacol Exp Ther 302: 8-17, 2002.

32. Jiang M, Wang CY, Huang S, Yang T and Dong Z: Cisplatininduced apoptosis in p53-deficient renal cells via the intrinsic mitochondrial pathway. Am J Physiol Renal Physiol 296: F983-F993, 2009. 